\title{
Scanning the horizon
}

\author{
We live in uncertain times, but the changing of the year provides a time not only to look back on the year that has \\ passed, but also to look forward to what might happen in the year to come.
}

t $\mathrm{n}$ the week this editorial is being written, the British Prime Minister, Theresa May, postponed a vote on the details of the United Kingdom's future relationship with the European Union (EU) because her proposals would have had so little support in Parliament; after which a vote of no confidence in her leadership was held by the Conservative Party, which she won by 200 votes to 117 by promising to resign before the next general election in 2022. And those are just the events in Britain. There have been riots on the streets in France; the US President's lawyer, Michael Cohen, has been jailed for campaign finance and fraud offences; and much else besides. Against such a backdrop, it may seem foolish to try to look ahead to what may occur during the next 12 months, even in the relatively restricted field of plant science, but nevertheless we can try.

As mentioned above, 2019 should bring some clarity on the future relationship between the UK and the EU. The UK is due to leave this political and economic union on 29 March 2019, or at least start to withdraw. This will certainly have an effect on European science as a whole, and plant science in particular. Of primary importance is the question as to whether scientists will be able to move between countries to pursue their research. The UK and Europe are both powerhouses of plant research. If evidence were needed, the UK produces the fourth highest number of submissions to Nature Plants of any country (exceeded only by China, the USA and Japan), but this number is dwarfed by the combined submissions of the other EU countries - we publish more papers from European labs than from any other continent.

But the above statistics only document the geographical location of the principle investigators on papers, not their nationalities. The Royal Society has estimated that more than a third of postgraduate research students in the UK hail from other European countries, while less than half are British nationals (https:// go.nature.com/2EndyRU). In a letter sent to the Home Secretary, Sajid Javid, on 16 November 2018, the four UK National Academy Presidents, including the President of the Royal Society, Venki Ramakrishnan, warned that if the UK were to employ the same regulations on European scientists as those that already exist for scientists from the rest of the world, "this could treble the number of science and research visas being issued annually and it is not clear that the existing system and universities and businesses are equipped for this increased burden" (https://go.nature.com/2Lk2kz7).

There are also uncertainties over the funding of science in Europe. Collaborations between UK and European labs are extremely common, especially in plant sciences. Many of these collaborations have been funded by grants from European funding agencies, prominent among them being the European Research Council. It is to be hoped that these can continue to fund both UK research and EU/UK collaborations, but until the details of the UK's exit from the EU are known there is no certainty, and uncertainties over funding are a surefire way to stifle research.

Looking more globally, the United Nations has designated 2019 the International Year of the Periodic Table. It is a little difficult to see how this might impinge on plant biologists, although the problems of phosphorus, nitrogen and potassium availability for agriculture continue to loom large. Equally, such a focus on elements may stimulate interest in the breeding or engineering of crops enhanced in essential dietary micronutrients, such as copper, molybdenum or zinc, deficiencies of which can lead to 'hidden hungers' of populations superficially well-supplied with staple crops. Additionally, 2019 is the United Nations Educational, Scientific and Cultural Organization (UNESCO) International Year of Indigenous Languages, which may shine a spotlight on ethnobotany.

Possibly more significantly, the coming year will see an election for the post of Director General of the Food and Agriculture Organization of the United Nations (FAO). The current Director General, Brazilian agronomist José Graziano da Silva, is coming to the end of his second four-year term, the same tenure as the previous three director generals. As the head of a global, yet politically neutral organization dedicated to monitoring world agriculture and helping formulate policies to increase its efficiency and sustainability, this individual will have a singular role in delivering the UN's sustainable development goals to abolish both hunger and poverty.
Candidates for the post will be announced in February, with elections taking place in June.

It seems safe to bet that establishing sustainable agriculture in the face of climate change will continue to dominate the applied aspects of plant science, as it has done for several years now. Altmetics, the organization that produces metrics and qualitative data intended to be complementary to citationbased analyses, have just released their top 100 research papers of the year. We were pleased to find two Nature Plants papers on the list, both related to climate change. One was the study of recent deaths of particularly ancient Baobab trees in Africa (Nat. Plants 4, 423-426; 2018), for which climate change is a possible explanation. The other, ranked nineteenth on the list, made predictions about future global barley yields and the production of beer (Nat. Plants 4, 964-973; 2018).

We are also anticipating that the development of long-read technologies (for example, see our paper from last November: Nat. Plants 4, 879-887; 2018) will have a big impact on plant genomics research this year, due to faster and more accurate assemblies of genomes and better coverage of difficult-tosequence, repetitive regions of chromosomes. It also seems likely that artificial intelligence (AI) will make its presence felt in the study of plants. There have already been some attempts to include machine learning into phenotyping, such as last year's work from researchers at the University of Edinburgh entitled: "Pheno-Deep Counter: a unified and versatile deep learning architecture for leaf counting" (Plant J. 96, 880-890; 2018), but more uses will doubtless follow, if not in 2019 then soon. One thing we are definitely looking forward to in June 2019 is a conference that we are running in conjunction with our colleagues at Nature Genetics and New York University on "Plants of the Future" (https:// go.nature.com/2rEWEXt). It should be a good couple of days and will cover a number of the topics mentioned above.

As Nature Plants begins its fifth year, and despite the myriad uncertainties to be faced at local, national and global levels, we are confident that there will be much to excite and inspire in 2019, both within our pages and without.

Published online: 9 January 2019 https://doi.org/10.1038/s41477-018-0353-0 